\title{
A rapid and cost-effective method for genotyping apolipoprotein E gene polymorphism
}

\author{
Li Zhong ${ }^{1}$, Yong-Zhuang Xie ${ }^{1}$, Tian-Tian Cao ${ }^{1}$, Zongqi Wang ${ }^{1}$, Tingting Wang ${ }^{1}$, Xinxiu Li ${ }^{1}$, Rui-Chi Shen², Huaxi Xu', \\ Guojun $\mathrm{Bu}^{1,3}$ and Xiao-Fen Chen ${ }^{1 *}$
}

\begin{abstract}
Background: Apolipoprotein E (ApoE) is a major cholesterol carrier and plays an important role in maintaining lipid homeostasis both in the periphery and brain. Human APOE gene is polymorphic at two single nucleotides (rs429358 and rs7412) resulting in three different alleles ( $\varepsilon 2, \varepsilon 3$ and $\varepsilon 4)$. ApoE isoforms modulate the risk for a variety of vascular and neurodegenerative diseases; thus, APOE genotyping is crucial for predicting disease risk and designing individualized therapy based on APOE genotype.

Results: We have developed an APOE genotyping method that is based on allele-specific PCR methodology adapted to Real Time PCR monitored by TaqMan probe. Rather than using TaqMan probes specific for the two polymorphic sites, only one TaqMan probe is used as the polymorphic alleles are recognized by site-specific PCR primers. Each genotyping assay can be completed within 90 minutes and is applicable to high-throughput analysis. Using this protocol, we genotyped a total of 1158 human DNA samples and obtained a $100 \%$ concordance with the APOE genotype determined by sequencing analysis.

Conclusion: The APOE genotyping assay we have developed is accurate and cost-effective. In addition, our assay can readily be applied to genotyping large sample numbers. Therefore, our APOE genotyping method can be used for assessing the risk for a variety of vascular and neurodegenerative diseases that have been reported to be associated with APOE polymorphism.
\end{abstract}

Keywords: Apolipoprotein E, APOE genotype, Real Time PCR, Sequencing, TaqMan, Polymorphism

\section{Background}

The human apolipoprotein $\mathrm{E}$ (apoE) gene is mapped to chromosome 19q13.2, which consists of four exons and three introns [1]. APOE gene is polymorphic at two single nucleotides (rs429358 and rs7412), resulting in three different alleles $(\varepsilon 2, \varepsilon 3$ and $\varepsilon 4)$ and six $A P O E$ genotypes $(\varepsilon 2 / \varepsilon 2, \varepsilon 2 / \varepsilon 3, \varepsilon 2 / \varepsilon 4, \varepsilon 3 / \varepsilon 3, \varepsilon 3 / \varepsilon 4$ and $\varepsilon 4 / \varepsilon 4)$ [2]. The worldwide frequency of $\varepsilon 2, \varepsilon 3$ and $\varepsilon 4$ allele is $8.4 \%$, $77.9 \%$ and $13.7 \%$, respectively $[3,4]$. However, the $A P O E$ allele frequencies vary widely among different ethnic populations [5]. Differences among the three apoE isoforms reside in the amino acid residues 112 and 158,

\footnotetext{
* Correspondence: chenxf@xmu.edu.cn

${ }^{1}$ Fujian Provincial Key Laboratory of Neurodegenerative Disease and Aging Research, Institute of Neuroscience, Medical College, Xiamen University, Xiamen 361102, China

Full list of author information is available at the end of the article
}

where either cysteine or arginine is present: E2 (Cys 112, Cys 158), E3 (Cys 112, Arg 158), and E4 (Arg 112, Arg 158) [6]. Despite differences by only one or two amino acids, the structural and functional differences among the three apoE isoforms can be profound to affect disease risk $[7,8]$.

ApoE is a major cholesterol carrier and plays an important role in maintaining lipid homeostasis both in the periphery and brain $[3,6]$. In the periphery, apoE is synthesized predominantly by liver and macrophages. In the brain, apoE is produced primarily by astrocytes and delivers cholesterol and other essential lipids to neurons through members of the low-density lipoprotein receptor (LDLR) family [9-12]. The single amino acid differences among the three apoE isoforms alter the protein's structure and influence its lipid association and receptor 
binding; therefore apoE modulates cholesterol homeostasis in an isoform-dependent manner [13]. Notably, apoE2 binds to LDLR with $\sim 50$-fold weaker affinity than apoE3 and apoE4. As a result, apoE2 transports lipids less efficiently, and $\varepsilon 2$ homozygosity is associated with an increased risk for type III hyperlipoproteinemia [14-16]. ApoE4 preferentially binds to large lipoprotein particles and is associated with increased risk for hypercholesterolemia and atherosclerosis, faster HIV disease progression, and accelerated telomere shortening [3, 17, 18].

Most importantly, genome-wide association studies have confirmed that the $\varepsilon 4$ allele of $A P O E$ is the strongest genetic risk factor for late-onset Alzheimer's disease (LOAD) [9, 19-21]. Compared with those with an $\varepsilon 3 / \varepsilon 3$ genotype, the risk of $\mathrm{AD}$ was increased in individuals with one copy $(\varepsilon 2 / \varepsilon 4$, OR 2.6 ; $\varepsilon 3 / \varepsilon 4$, OR 3.2$)$ or two copies $(\varepsilon 4 / \varepsilon 4$, OR 14.9) of the $\varepsilon 4$ allele [4, 22, 23]. Conversely, the $\varepsilon 2$ allele of $A P O E$ has a protective effect against $\mathrm{AD}$ [24]. The risk of $\mathrm{AD}$ in individuals carrying an $\varepsilon 2 / \varepsilon 2(\mathrm{OR} 0.6)$ or $\varepsilon 2 / \varepsilon 3$ (OR 0.6$)$ genotype is lower than those carrying $\varepsilon 3 / \varepsilon 3$ [4]. Additionally, the $\varepsilon 4$ allele of $A P O E$ was found to be a risk factor for other neurodegenerative diseases including cerebral amyloid angiopathy (CAA) [25], dementia with Lewy bodies [26, 27] and multiple sclerosis [28].

As $A P O E$ genotype predicts the risk for a variety of vascular and neurodegenerative diseases, it is critical to develop rapid and cost-effective methods to analyze $A P O E$ gene polymorphism. Several different $A P O E$ genotyping methods have been developed. Among them, the PCR-Restriction Fragment Length Polymorphism (PCRRFLP) analysis is a conventional method applied to genotype $A P O E$ polymorphism [29, 30]. However, this method is complex and labor-intensive as it involves multiple steps including restriction enzyme digestion. PCR plus sequencing or mass spectrometry is an effective method, but requires expensive detection equipment and is also labor-intensive [31]. Several Real Time PCR-based techniques have been developed to genotype $A P O E$ gene, including HRM (high resolution melt) [32, 33], TaqMan probe [34] and FRET (Fluorescent Resonance Energy Transfer) [35]. However, the formation of primer-dimers may complicate the melting curves interpretation, and the use of FRET and multiple TaqMan probes is in general costly.

In view of the importance of $A P O E$ genotyping in predicting individual risk for a variety of vascular and neurodegenerative diseases, we have developed a rapid and cost-effective method for analyzing $A P O E$ polymorphism. Using this protocol, we genotyped a total of 1158 human DNA samples and obtained a $100 \%$ concordance with the $A P O E$ genotype determined by sequencing analysis. Therefore, the method we have developed for
$A P O E$ genotyping is precise and suitable for genotyping large sample cohorts.

\section{Results \\ APOE genotyping assay development and validation}

Our assay was based on allele-specific PCR methodology adapted to Real Time PCR monitored by TaqMan probe. Initial PCR primers were designed according to the nucleotide differences located at the two SNPs within exon 4 of the $A P O E$ gene, rs429358 and rs7412 (Fig. 1a). We screened a group of oligonucleotide primers and obtained three pairs that gave specific amplifications of $\varepsilon 2$, $\varepsilon 3$ and $\varepsilon 4$ allele, respectively (Table 1 ). In order to monitor real-time DNA amplification products, one doubledye oligonucleotide TaqMan probe was included in all reactions. The probe has a FAM fluorophore attached to its 5' end and a BHQ quencher molecule attached to its 3' end (Fig. 1b). The probe initially hybridizes to the template strand via its complementary sequences. Upon PCR amplification, Taq polymerase will degrade the probe during strand extension, resulting in the separation of fluorophore and the quencher which allows the excitation of the fluorophore by laser [36].

To validate the efficiency and specificity of our assay, we synthesized three 197-bp DNA sequences covering the two SNPs for $\varepsilon 2$, $\varepsilon 3$ or $\varepsilon 4$ allele and a 179-bp DNA sequence of beta-actin gene $(A C T B)$ which serve as positive controls for $A P O E$ genotyping. The TaqMan probe for $A C T B$ was designed similar to $A P O E$ but the former has a HEX fluorophore attached to its 5 ' end. Genotyping of each sample was carried out in parallel reactions, namely $\varepsilon 2, \varepsilon 3$ or $\varepsilon 4$ reaction. Each reaction contains allele-specific primers for $A P O E$ in combination with the primers for $A C T B$. Specific amplification curve appeared only in $\varepsilon 2$ reaction when $\varepsilon 2$-positive DNA was used (Fig. 2). Similar results were observed in $\varepsilon 3$ or $\varepsilon 4$ reaction, demonstrating the specificity of our detecting system.

\section{APOE genotyping of clinical DNA samples}

We further validated our $A P O E$ genotyping assay using human DNA samples. Genomic DNA was extracted from 1158 clinical blood samples and undergone subsequent $A P O E$ genotyping analysis. The presence/absence of haplotypes was either determined by differential amplification with the three specific amplification setups for $\varepsilon 2$, $\varepsilon 3$ or $\varepsilon 4$ allele, or by DNA sequencing performed by Sangon Biotech using the ABI 3730XL DNA Sequencer. In the clinical sample testing, our $A P O E$ genotyping assay has been efficient such that a single Real Time PCR reaction took approximately 90 minutes, and the Roche LightCycler 480 II system has the potential to run 384 reactions at one time. Typical results are presented in Fig. 3, 


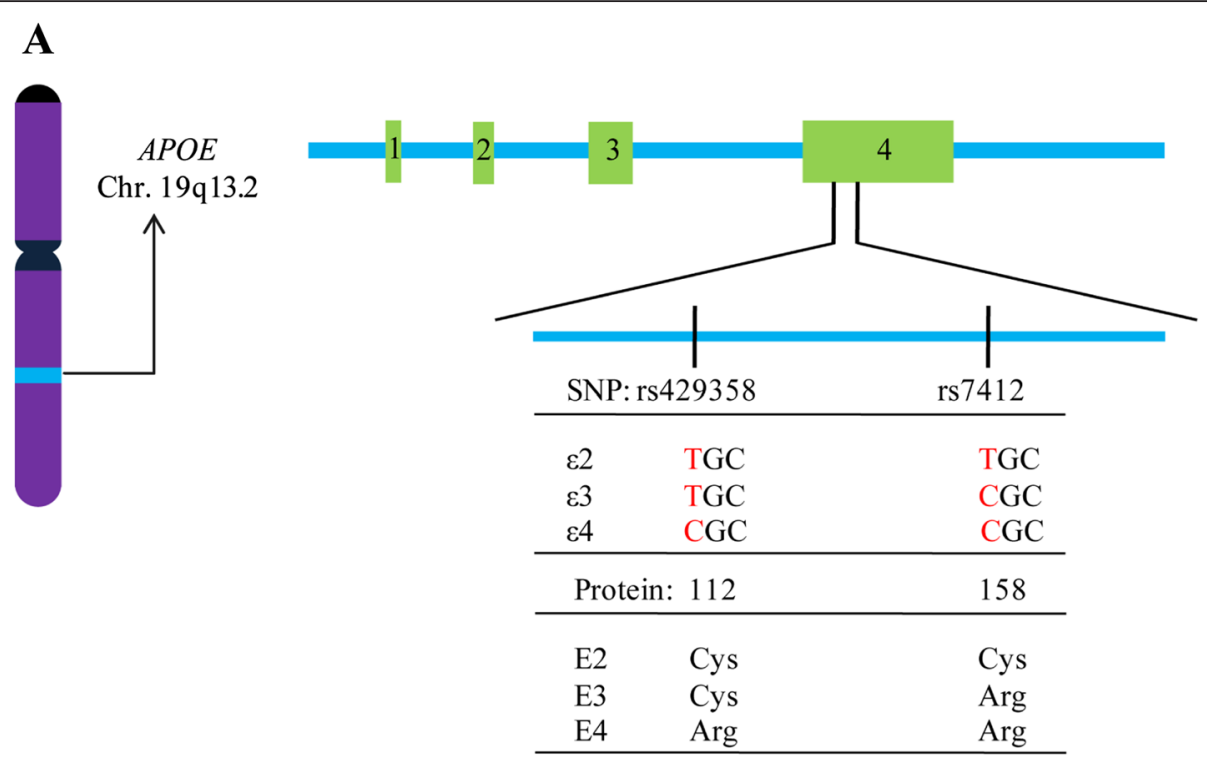

B

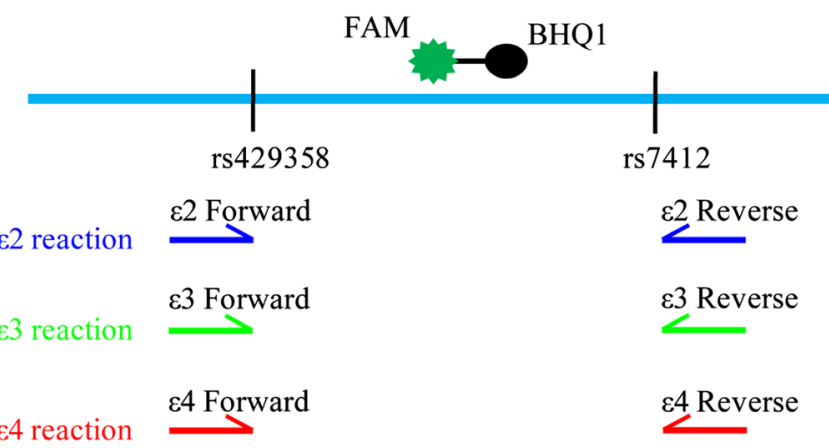

Fig. 1 Schematic diagram of the human APOE gene and APOE genotyping method. a The APOE gene is located on chromosome 19, and is polymorphic at two single nucleotides (rs429358 and rs7412) resulting in three different alleles ( $\varepsilon 2, \varepsilon 3$ and $\varepsilon 4$ ). b Amplifications of the APOE $\varepsilon 2$, $\varepsilon 3$ and $\varepsilon 4$ alleles are initiated by allele-specific PCR primers. One double-dye oligonucleotide TaqMan probe was included in all reactions to monitor real-time DNA amplification products

Table 1 Sequences of primers and probes for the APOE genotyping assay

\begin{tabular}{ll}
\hline Name & Sequence $\left(5^{\prime}\right.$-3') \\
\hline$\varepsilon 2$-Forward & GCGGACATGGAGGACGTGT \\
$\varepsilon 2-$ Reverse & CCTGGTACACTGCCAGGCA \\
$\varepsilon 3$-Forward & CGGACATGGAGGACGTGT \\
$\varepsilon 3-$ Reverse & CTGGTACACTGCCAGGCG \\
$\varepsilon 4-$ Forward & CGGACATGGAGGACGTGC \\
$\varepsilon 4-$ Reverse & CTGGTACACTGCCAGGCG \\
APOE probe & FAM-CAGCTCCTCGGTGCTCTGGC-BHQ1 \\
ACTB-Forward & GACGTGGACATCCGCAAAGAC \\
ACTB-Reverse & CAGGTCAGCTCAGGCAGGAA \\
ACTB probe & HEX-TGCTGTCTGGCGGCACCACCATGTACC-BHQ1 \\
\hline
\end{tabular}

with genotyping results and allele frequencies summarized in Table 2. APOE genotyping using our assay showed $100 \%$ concordance with DNA sequencing results, demonstrating the accuracy and reliability of our protocol. The APOE allele frequency for $\varepsilon 2, \varepsilon 3$ and $\varepsilon 4$ in our Chinese Han population was $7.90 \%$, $83.94 \%, 8.16 \%$, respectively. Thus, the frequency of the $\varepsilon 4$ allele was lower than that for the world-wide population (8.4\%, $77.9 \%$ and $13.7 \%$ for $\varepsilon 2$, $\varepsilon 3$ and $\varepsilon 4$, respectively), but was similar to previous studies in Chinese population [4, 5, 37]. To provide guidance on evaluating the accuracy of our $A P O E$ genotyping method, receiver operating characteristic (ROC) curve analysis was performed to assess the cut-off $\Delta \mathrm{Ct}$ values for each Real Time PCR reaction (Table 3). A sample is considered to be negative for the corresponding genotype analysis if the $\Delta \mathrm{Ct}$ value is higher than the cut-off value. 


\section{APOE}

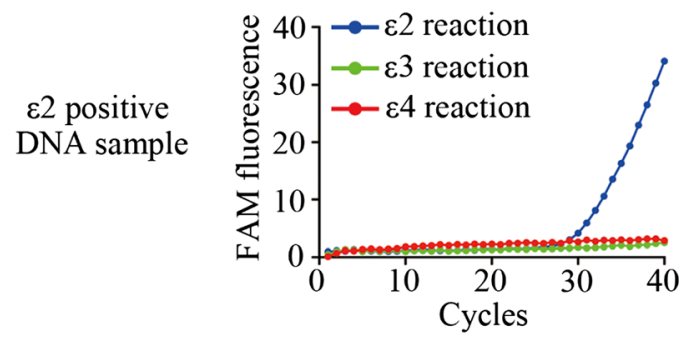

$\varepsilon 3$ positive

DNA sample

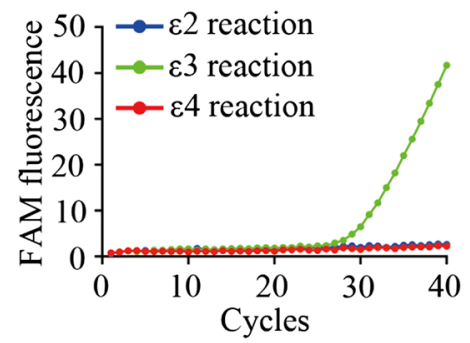

$\varepsilon 4$ positive

DNA sample

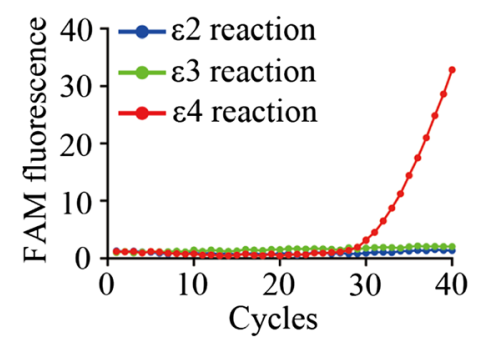

ACTB
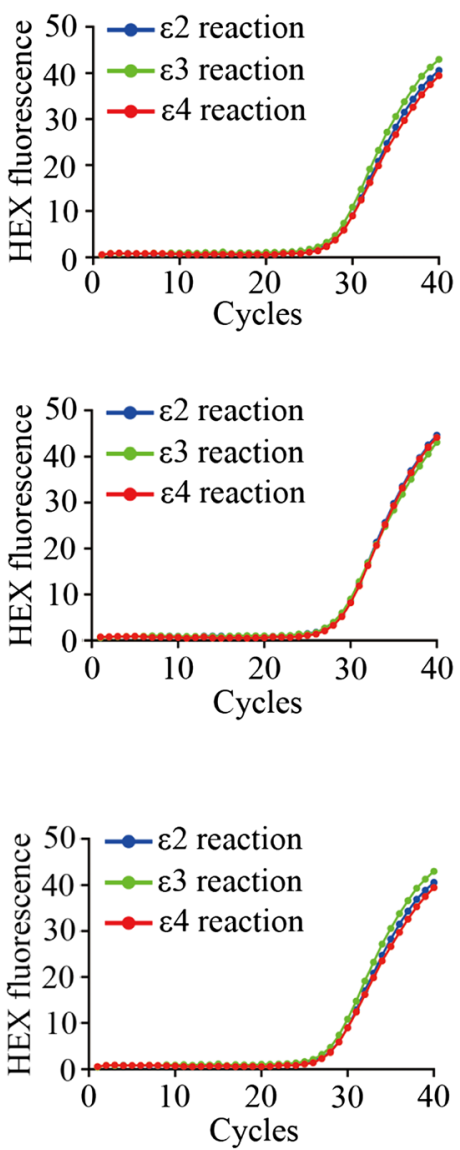

Fig. 2 APOE genotyping on $\varepsilon 2-, \varepsilon 3-$ or $\varepsilon 4$-positive plasmid DNA by Real Time PCR. Representative amplification curves for APOE and ACTB are shown. 12000 copies of each plasmid DNA are used as templates. Blue: $\varepsilon 2$ reaction; Green: $\varepsilon 3$ reaction; Red: $\varepsilon 4$ reaction. FAM fluorescence: APOE gene; HEX fluorescence: ACTB gene

\section{Discussion}

We have developed an $A P O E$ genotyping assay that is based on allele-specific PCR methodology adapted to Real Time PCR monitored by a common TaqMan probe. Each genotyping analysis can be accomplished within 90 minutes and is applicable to high-throughput analysis. We validated the specificity and robustness of our assay in 1158 clinical DNA samples by comparing the results with those from DNA sequencing. All samples genotyped using our assay showed perfect concordance with the $A P O E$ genotypes determined by sequencing analysis. Therefore, our method for $A P O E$ genotyping is rapid, precise and cost-effective, with the potential for high-throughput application.

$A P O E$ gene polymorphism modulates the risk for a variety of vascular and neurodegenerative diseases; thus, $A P O E$ genotyping is crucial for predicting disease risk and designing individualized therapy based on $A P O E$ genotype. Recent studies have suggested that therapeutic interventions applied earlier in the course of $\mathrm{AD}$ might be more likely to achieve disease modification. Indeed, there is a growing recognition that the pathophysiological process of $\mathrm{AD}$ begins many years prior to the onset of clinical symptoms [38]. APOE \&4 allele is the strongest genetic risk factor for $\mathrm{AD}$. The mean age of onset and frequency of $\mathrm{AD}$ are 68 years and $91 \%$ in $\varepsilon 4$ homozygotes, 76 years and $47 \%$ in $\varepsilon 4$ heterozygotes, 84 years and $20 \%$ in $\varepsilon 4$ non-carriers [39]. Intriguingly, apoE4 has been associated with greater efficacy in at least two clinical trials on mild cognitive impairment $[40,41]$. Taken together, $A P O E$ genotype status may add predictive value to the clinical diagnosis and evaluation of treatment efficacy $[8,42]$. Developing an accurate and reliable method for $A P O E$ genotyping is therefore crucial for $\mathrm{AD}$ diagnosis and therapy.

PCR-RFLP analysis is a conventional method for APOE genotyping, but is relatively error-prone and laborintensive due to a number of reaction steps $[29,30]$. 


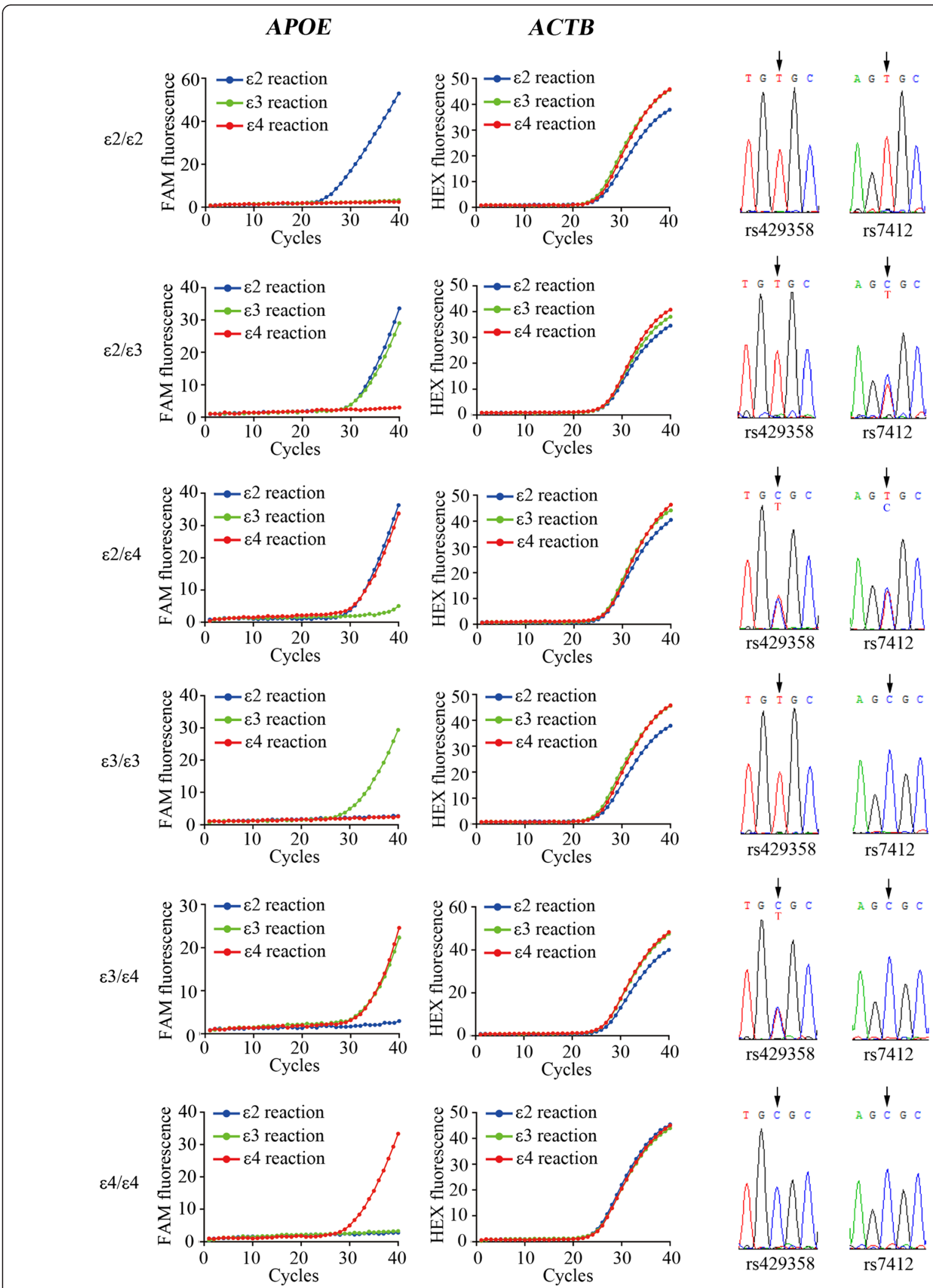

Fig. 3 APOE genotyping on clinical DNA samples by Real Time PCR and DNA sequencing. Representative amplification curves for APOE and ACTB, and representative sequencing results for the two SNPs (rs429358 and rs7412) are shown. Blue: $\varepsilon 2$ reaction; Green: $\varepsilon 3$ reaction; Red: $\varepsilon 4$ reaction. FAM fluorescence: APOE gene; HEX fluorescence: ACTB gene 
Table 2 Analysis of APOE genotypes and allele frequency in Chinese population

\begin{tabular}{|c|c|c|c|c|c|c|c|c|c|c|c|}
\hline \multirow[t]{2}{*}{ Cohort } & \multirow[t]{2}{*}{ No. } & \multicolumn{6}{|c|}{ APOE genotypes (No.) } & \multirow[t]{2}{*}{ Accuracy (\%) } & \multicolumn{3}{|c|}{ Alleles (\%) } \\
\hline & & $\varepsilon 2 / \varepsilon 2$ & $\varepsilon 2 / \varepsilon 3$ & $\varepsilon 2 / \varepsilon 4$ & $\varepsilon 3 / \varepsilon 3$ & $\varepsilon 3 / \varepsilon 4$ & $\varepsilon 4 / \varepsilon 4$ & & $\varepsilon 2$ & $\varepsilon 3$ & $\varepsilon 4$ \\
\hline Zhongshan & 399 & 2 & 60 & 6 & 278 & 51 & 2 & 100 & 8.77 & 83.58 & 7.65 \\
\hline Fujian & 390 & 2 & 50 & 5 & 271 & 60 & 2 & 100 & 7.56 & 83.59 & 8.85 \\
\hline Huadong & 369 & 3 & 43 & 5 & 265 & 52 & 1 & 100 & 7.32 & 84.69 & 7.99 \\
\hline Total & 1158 & 7 & 153 & 16 & 814 & 163 & 5 & 100 & 7.90 & 83.94 & 8.16 \\
\hline
\end{tabular}

Genomic DNA was extracted from peripheral blood samples obtained from three hospitals (399 samples from Zhongshan Hospital Affiliated to Xiamen University, 390 samples from Fujian Medical University Union Hospital, and 369 samples from Huadong Hospital Affiliated to Fudan University). The APOE genotypes and allele frequency were analyzed by both Real Time PCR and DNA sequencing. The $100 \%$ accuracy was defined when APOE genotyping using the Real Time PCR assay showed $100 \%$ concordance with DNA sequencing results

Compared with the PCR-RFLP method, the accuracy of our $A P O E$ genotyping method was improved by reducing the steps to one PCR reaction in closed PCR tubes and with no post-PCR sample handling. DNA sequencing is an accurate method for $A P O E$ genotyping, but it is laborintensive and not suitable for high-throughput analysis. Our assay was based on allele-specific PCR methodology and possesses the potential for high-throughput application. Several Real Time PCR-based techniques have been developed to genotype $A P O E$ alleles, but the formation of primer-dimers makes the interpretation of the melting curves at times difficult [32, 33]. In our protocol, we provide guidance on threshold selection to evaluate the performance of PCR amplification by ROC analysis; therefore, the sensitivity and specificity of our protocol are well defined. TaqMan systems for $A P O E$ genotyping have been developed for the single nucleotide polymorphisms at rs429358 and rs7412 [34, 43]. However, most protocols require the use of four costly TaqMan probes. Only one TaqMan probe is used in our method as the polymorphic alleles are recognized by site-specific PCR primers. Thus, our method has the potential to design high-throughput application in a way that is cost-effective.

\section{Conclusions}

In this work, we present an $A P O E$ genotyping method that is accurate and cost-effective. In addition, our assay is based on allele-specific PCR methodology; therefore, can readily be applied to high-throughput $A P O E$ genotyping. Our $A P O E$ genotyping protocol can be used in addressing the impact of $A P O E$ polymorphism on

Table 3 Cut-off values for $\Delta C t$ calculated by ROC curve analysis

\begin{tabular}{lc}
\hline Reactions & Cut-off values \\
\hline$\varepsilon 2$ reaction & 9.2 \\
$\varepsilon 3$ reaction & 10.4 \\
$\varepsilon 4$ reaction & 11.1 \\
\hline
\end{tabular}

The cut-off $\Delta \mathrm{Ct}$ values for the three reactions were calculated from ROC curve analysis, which represent the threshold cycle above which a sample is considered to be negative for the corresponding genotype analysis disease risk, and notably in clinical assessments that predict the risk for a variety of vascular and neurodegenerative diseases.

\section{Methods \\ Subjects}

A total of 1158 peripheral blood samples were collected from the clinical laboratories in three hospitals (399 samples from Zhongshan Hospital Affiliated to Xiamen University, 390 samples from Fujian Medical University Union Hospital, and 369 samples from Huadong Hospital Affiliated to Fudan University). The study was performed in accordance with the Declaration of Helsinki and approved by the Ethics Committees of the three hospitals.

\section{DNA constructs and reagents}

All PCR primers and TaqMan probes were synthesized and purified by Life Technologies (Table 1). Three 197bp DNA sequences covering the two SNPs for APOE $\varepsilon 2$, $\varepsilon 3$ or $\varepsilon 4$ allele and a 179-bp DNA sequence of beta-actin gene $(A C T B)$ were synthesized and cloned into pUC57 vector, which served as positive control DNA templates (Sangon Biotech, Shanghai, China). All constructs were verified by DNA sequencing (Sangon Biotech, Shanghai, China). Premix PrimeSTAR HS (R040A) was purchased from TAKARA; TaqMan ${ }^{\circ}$ Genotyping Master Mix (4371357) was purchased from Applied Biosystems; DMSO (D2650) was purchased from Sigma; and blood DNA extraction kit (DP348-03) was purchased from TIANGEN (TIANGEN, Beijing, China).

\section{Human genomic DNA isolation}

Genomic DNA was extracted from $400 \mu \mathrm{L}$ peripheral blood by using the blood DNA extraction kit (TIANGEN) according to the manufacturer's instructions. DNA was diluted with nuclease free water to $8 \mathrm{ng} / \mu \mathrm{L}$ for $A P O E$ genotyping analysis. 


\section{APOE genotyping by Real Time PCR}

$A P O E$ genotyping by Real Time PCR includes three reactions: $\varepsilon 2$ reaction (primers $\varepsilon 2$-Forward and $\varepsilon 2$-Reverse), $\varepsilon 3$ reaction (primers $\varepsilon 3$-Forward and $\varepsilon 3$-Reverse) and $\varepsilon 4$ reaction (primers $\varepsilon 4$-Forward and $\varepsilon 4$-Reverse). Each PCR reaction mixture $(15 \mu \mathrm{L})$ contained the following reagents: $1 \times$ TaqMan $^{\circ}$ Genotyping Master Mix, $0.5 \mu \mathrm{M}$ of each $A P O E$ primer and $A P O E$ probe, $0.1 \mu \mathrm{M}$ of each $A C T B$ primer and $A C T B$ probe, $40 \mathrm{ng}$ of genomic DNA. Positive control DNA template $(\varepsilon 2, \varepsilon 3, \varepsilon 4$ plasmid DNA) and negative control (DNA/RNA-free water) were included in each panel of genotyping. The PCR amplification protocol was as follows: Initial activation of AmpliTaq Gold DNA Polymerase at $95^{\circ} \mathrm{C}$ for $10 \mathrm{~min}$, followed by 40 cycles with denaturation at $95{ }^{\circ} \mathrm{C}$ for $15 \mathrm{sec}$, and annealing/extension at $64{ }^{\circ} \mathrm{C}$ for $1 \mathrm{~min}$. The fluorescence signals were collected during the annealing/extension step. FAM signal indicates $A P O E$ alleles and HEX signal indicates $A C T B$ gene (internal control). The amplification was performed by using the Roche LightCycler 480 II system (Roche).

\section{APOE genotyping by sequencing}

For validation purpose, results by the above-mentioned $A P O E$ genotyping assay were compared with those from DNA sequencing analysis. Briefly, $A P O E$ gene fragments encompassing the two SNPs were amplified. The amplification reaction was carried out in a volume of $50 \mu \mathrm{L}$, which cotains $1 \times$ Premix PrimeSTAR HS, $0.2 \mu \mathrm{M}$ of each primer (Forward primer: 5'-AGCCCTTCTCCCC GCCTCCCACTGT-3' and Reverse primer: 5'-CTCC GCCACCTGCTCCTTCACCTCG-3'), 5 \% DMSO and 40 ng genomic DNA. The PCR cycling conditions were as follows: Initial denaturation at $98{ }^{\circ} \mathrm{C}$ for $4 \mathrm{~min}$ followed by 35 cycles with denaturation at $98{ }^{\circ} \mathrm{C}$ for $10 \mathrm{sec}$, annealing at $60{ }^{\circ} \mathrm{C}$ for $30 \mathrm{sec}$, extension at $72{ }^{\circ} \mathrm{C}$ for $40 \mathrm{sec}$; then a final extension at $72{ }^{\circ} \mathrm{C}$ for $10 \mathrm{~min}$. All PCR products were purified and sequenced by Sangon Biotech using the ABI 3730XL DNA Sequencer (Applied Biosystems).

\section{Ct cut-off values calculated by ROC curve analysis}

The APOE genotypes of 114 human genomic DNA samples were determined either by our $A P O E$ genotyping method or by DNA sequencing. Receiver operating characteristic (ROC) curve analysis was performed to calculate the cut-off values for $\Delta \mathrm{Ct}$ (calculated by subtracting the $\mathrm{Ct}$ value of HEX signal from the $\mathrm{Ct}$ value of FAM signal) in our $A P O E$ genotyping assay. If no amplification curve appeared in the $A P O E$ allele-specific reaction, the $\mathrm{Ct}$ value was considered as 40 for the calculation of $\Delta \mathrm{Ct}$. The $\Delta \mathrm{Ct}$ values of the $\varepsilon 2 / \varepsilon 3 / \varepsilon 4$ reaction were 9.2 , 10.4 and 11.1, respectively, as calculated by ROC curve analysis using SPSS software (Table 3).

\section{Abbreviations}

AD: Alzheimer's disease; ApoE: Apolipoprotein E; CAA: cerebral amyloid angiopathy; Ct: cycle threshold; FAM: carboxyfluorescein; FRET: fluorescent resonance energy transfer; HEX: hexachloro fluorescein; HRM: high resolution melt; LDLR: low-density lipoprotein receptor; LOAD: late-onset Alzheimer's disease; RFLP: restriction fragment length polymorphism; ROC: receiver operating characteristic; SNP: single nucleotide polymorphism.

\section{Competing interests}

The authors declare that they have no competing interests.

\section{Authors' contributions}

Conceived and designed the experiments: GB, XC, LZ and HX. Performed the experiments and analyzed the data: $L Z, Y X, T C, Z W, T W, X L$ and RS. Wrote the paper: XC, LZ and GB. All authors read and approved the final manuscript.

\section{Acknowledgments}

The authors are grateful to all subjects for participation in our study. This study was supported by grants $(81370459,31400914)$ from the National Natural Science Foundation of China (to X.C.), the Fundamental Research Funds for the Central Universities (20720150051, to X.C.), NIH grants (R01AG027924, R01AG035355, R01AG046205, to G.B.), and grant from Xiamen Science and Technology Bureau (2014S0505, to HX).

\section{Author details}

${ }^{1}$ Fujian Provincial Key Laboratory of Neurodegenerative Disease and Aging Research, Institute of Neuroscience, Medical College, Xiamen University, Xiamen 361102, China. ${ }^{2}$ Fujian Institute of Subtropical Botany, Xiamen 361006, China. ${ }^{3}$ Department of Neuroscience, Mayo Clinic, Jacksonville, FL 32224, USA.

Received: 30 November 2015 Accepted: 4 January 2016 Published online: 12 January 2016

\section{References}

1. Das HK, McPherson J, Bruns GA, Karathanasis SK, Breslow JL. Isolation, characterization, and mapping to chromosome 19 of the human apolipoprotein E gene. J Biol Chem. 1985;260:6240-7.

2. Mahley RW, Nathan BP, Pitas RE. Apolipoprotein E. Structure, function, and possible roles in Alzheimer's disease. Ann N Y Acad Sci. 1996;777:139-45.

3. Mahley RW. Apolipoprotein E: cholesterol transport protein with expanding role in cell biology. Science. 1988:240:622-30.

4. Farrer LA, Cupples LA, Haines JL, Hyman B, Kukull WA, Mayeux R, et al. Effects of age, sex, and ethnicity on the association between apolipoprotein E genotype and Alzheimer disease. A meta-analysis. APOE and Alzheimer Disease Meta Analysis Consortium. JAMA. 1997:278:1349-56.

5. Corbo RM, Scacchi R. Apolipoprotein E (APOE) allele distribution in the world. Is APOE*4 a 'thrifty' allele? Ann Hum Genet. 1999;63:301-10.

6. Mahley RW, Rall Jr SC. Apolipoprotein E: far more than a lipid transport protein. Annu Rev Genomics Hum Genet. 2000;1:507-37.

7. Verghese PB, Castellano JM, Holtzman DM. Apolipoprotein E in Alzheimer's disease and other neurological disorders. Lancet Neurol. 2011;10:241-52.

8. Liu CC, Kanekiyo T, Xu H, Bu G. Apolipoprotein E and Alzheimer disease: risk mechanisms and therapy. Nat Rev Neurol. 2013;9:106-18.

9. Bu G. Apolipoprotein $\mathrm{E}$ and its receptors in Alzheimer's disease: pathways, pathogenesis and therapy. Nat Rev Neurosci. 2009;10:333-44.

10. Herz J, Chen Y. Reelin, lipoprotein receptors and synaptic plasticity. Nat Rev Neurosci. 2006;7:850-9.

11. Grehan S, Tse E, Taylor JM. Two distal downstream enhancers direct expression of the human apolipoprotein E gene to astrocytes in the brain. J Neurosci. 2001;21:812-22

12. Pitas RE, Boyles JK, Lee SH, Foss D, Mahley RW. Astrocytes synthesize apolipoprotein $\mathrm{E}$ and metabolize apolipoprotein E-containing lipoproteins. Biochim Biophys Acta. 1987:917:148-61.

13. Hatters DM, Peters-Libeu CA, Weisgraber KH. Apolipoprotein E structure: insights into function. Trends Biochem Sci. 2006;31:445-54.

14. Breslow JL, Zannis VI, SanGiacomo TR, Third JL, Tracy T, Glueck CJ. Studies of familial type III hyperlipoproteinemia using as a genetic marker the apoE phenotype E2/2. J Lipid Res. 1982;23:1224-35. 
15. Feussner G, Feussner V, Hoffmann MM, Lohrmann J, Wieland H, Marz W. Molecular basis of type III hyperlipoproteinemia in Germany. Hum Mutat. 1998;11:417-23.

16. Civeira F, Pocovi M, Cenarro A, Casao E, Vilella E, Joven J, et al. Apo E variants in patients with type III hyperlipoproteinemia. Atherosclerosis. 1996; 127:273-82.

17. Burt TD, Agan BK, Marconi VC, He W, Kulkarni H, Mold JE, et al. Apolipoprotein (apo) E4 enhances HIV-1 cell entry in vitro, and the APOE epsilon4/epsilon4 genotype accelerates HIV disease progression. Proc Natl Acad Sci U S A. 2008;105:8718-23.

18. Jacobs EG, Kroenke C, Lin J, Epel ES, Kenna HA, Blackburn EH, et al. Accelerated cell aging in female APOE-epsilon4 carriers: implications for hormone therapy use. PLoS One. 2013;8:e54713.

19. Rebeck GW, Reiter JS, Strickland DK, Hyman BT. Apolipoprotein E in sporadic Alzheimer's disease: allelic variation and receptor interactions. Neuron. 1993; 11:575-80

20. Saunders AM, Strittmatter WJ, Schmechel D, George-Hyslop PH, PericakVance MA, Joo SH, et al. Association of apolipoprotein E allele epsilon 4 with late-onset familial and sporadic Alzheimer's disease. Neurology. 1993; 43:1467-72

21. Strittmatter WJ, Saunders AM, Schmechel D, Pericak-Vance M, Enghild J, Salvesen GS, et al. Apolipoprotein E: high-avidity binding to beta-amyloid and increased frequency of type 4 allele in late-onset familial Alzheimer disease. Proc Natl Acad Sci U S A. 1993;90:1977-81.

22. McMurdo L, Lidbury PS, Corder R, Thiemermann C, Vane JR. Heterogeneous receptors mediate endothelin-1-induced changes in blood pressure, hematocrit, and platelet aggregation. J Cardiovasc Pharmacol. 1993;22 Suppl 8:S185-8.

23. Bertram L, Tanzi RE. Thirty years of Alzheimer's disease genetics: the implications of systematic meta-analyses. Nat Rev Neurosci. 2008:9:768-78.

24. Corder EH, Saunders AM, Risch NJ, Strittmatter WJ, Schmechel DE, Gaskell Jr PC, et al. Protective effect of apolipoprotein E type 2 allele for late onset Alzheimer disease. Nat Genet. 1994;7:180-4.

25. Greenberg SM, Rebeck GW, Vonsattel JP, Gomez-Isla T, Hyman BT. Apolipoprotein E epsilon 4 and cerebral hemorrhage associated with amyloid angiopathy. Ann Neurol. 1995;38:254-9.

26. Tsuang D, Leverenz JB, Lopez OL, Hamilton RL, Bennett DA, Schneider JA, et al. APOE epsilon4 increases risk for dementia in pure synucleinopathies. JAMA Neurol. 2013;70:223-8.

27. Bras J, Guerreiro R, Darwent L, Parkkinen L, Ansorge O, Escott-Price V, et al. Genetic analysis implicates APOE, SNCA and suggests lysosomal dysfunction in the etiology of dementia with Lewy bodies. Hum Mol Genet. 2014;23: 6139-46.

28. Masterman T, Hillert J. The telltale scan: APOE epsilon4 in multiple sclerosis. Lancet Neurol. 2004;3:331.

29. Hixson JE, Vernier DT. Restriction isotyping of human apolipoprotein E by gene amplification and cleavage with Hhal. J Lipid Res. 1990;31:545-8.

30. Zivelin A, Rosenberg N, Peretz H, Amit Y, Kornbrot N, Seligsohn U. Improved method for genotyping apolipoprotein E polymorphisms by a PCR-based assay simultaneously utilizing two distinct restriction enzymes. Clin Chem. 1997:43:1657-9.

31. Srinivasan JR, Kachman MT, Killeen AA, Akel N, Siemieniak D, Lubman DM. Genotyping of apolipoprotein E by matrix-assisted laser desorption/ ionization time-of-flight mass spectrometry. Rapid Commun Mass Spectrom. 1998:12:1045-50

32. Zhan XH, Zha GC, Jiao JW, Yang LY, Zhan XF, Chen JT, et al. Rapid identification of apolipoprotein E genotypes by high-resolution melting analysis in Chinese Han and African Fang populations. Exp Ther Med. 2015; 9:469-75.

33. Poulson MD, Wittwer CT. Closed-tube genotyping of apolipoprotein E by isolated-probe PCR with multiple unlabeled probes and high-resolution DNA melting analysis. Biotechniques. 2007;43:87-91.

34. Koch W, Ehrenhaft A, Griesser K, Pfeufer A, Muller J, Schomig A, et al. TaqMan systems for genotyping of disease-related polymorphisms present in the gene encoding apolipoprotein E. Clin Chem Lab Med. 2002:40:1123-31.

35. Calero O, Hortiguela R, Bullido MJ, Calero M. Apolipoprotein E genotyping method by real time PCR, a fast and cost-effective alternative to the TaqMan and FRET assays. J Neurosci Methods. 2009;183:238-40.

36. Holland PM, Abramson RD, Watson R, Gelfand DH. Detection of specific polymerase chain reaction product by utilizing the $5^{\prime}-\ldots 3^{\prime}$ exonuclease activity of Thermus aquaticus DNA polymerase. Proc Natl Acad Sci U S A. 1991:88:7276-80.

37. Seet WT, Mary Anne TJ, Yen TS. Apolipoprotein E genotyping in the Malay, Chinese and Indian ethnic groups in Malaysia-a study on the distribution of the different apoE alleles and genotypes. Clin Chim Acta. 2004;340:201-5.

38. Sperling RA, Aisen PS, Beckett LA, Bennett DA, Craft S, Fagan AM, et al. Toward defining the preclinical stages of Alzheimer's disease: recommendations from the National Institute on Aging-Alzheimer's Association workgroups on diagnostic guidelines for Alzheimer's disease. Alzheimers Dement. 2011;7:280-92.

39. Corder EH, Saunders AM, Strittmatter WJ, Schmechel DE, Gaskell PC, Small GW, et al. Gene dose of apolipoprotein E type 4 allele and the risk of Alzheimer's disease in late onset families. Science. 1993;261:921-3.

40. Poirier J, Delisle MC, Quirion R, Aubert I, Farlow M, Lahiri D, et al. Apolipoprotein E4 allele as a predictor of cholinergic deficits and treatment outcome in Alzheimer disease. Proc Natl Acad Sci U S A. 1995;92:12260-4.

41. Petersen RC, Thomas RG, Grundman M, Bennett D, Doody R, Ferris S, et al. Vitamin $\mathrm{E}$ and donepezil for the treatment of mild cognitive impairment. N Engl J Med. 2005;352:2379-88.

42. Farlow MR. Should the ApoE genotype be a covariate for clinical trials in Alzheimer disease? Alzheimers Res Ther. 2010;2:15.

43. Yi L, Wu T, Luo W, Zhou W, Wu J. A non-invasive, rapid method to genotype late-onset Alzheimer's disease-related apolipoprotein E gene polymorphisms. Neural Regen Res. 2014;9:69-75.

\section{Submit your next manuscript to BioMed Central and we will help you at every step:}

- We accept pre-submission inquiries

- Our selector tool helps you to find the most relevant journal

- We provide round the clock customer support

- Convenient online submission

- Thorough peer review

- Inclusion in PubMed and all major indexing services

- Maximum visibility for your research

Submit your manuscript at www.biomedcentral.com/submit
) Biomed Central 